\title{
Reflexões sobre a Construção do Conhecimento em Ambientes de Pesquisa e de Autoria Multimídia: Uma Tarefa Compartilhada por Alunos e Professores
}

\author{
Adriana Justin Cerveira Kampff* \\ Márcia Gladis Cantelli Dias ${ }^{* *}$
}

\section{Resumo}

Este artigo pretende colocar, de maneira sintética, a fundamentação teórica, as implicações pedagógicas e experiências de projetos desenvolvidos com pesquisa e autoria em ambientes multimídia, visando promover espaços mais ricos de aprendizagem. Com esse intuito, reflexões sobre as mudanças sociais e o papel da escola e do professor são colocadas de forma a motivar a incorporação das Novas Tecnologias da Comunicação e da Informação no ambiente escolar, através do trabalho com projetos. Estimulando a pesquisa, o compartilhamento de informações, o trabalho em grupo e, ao mesmo tempo, o desenvolvimento de competências individuais, buscou-se analisar os possíveis ganhos pedagógicos da atitude exploratória, favorecida em ambientes multimídia, e da construção ativa. As contribuições para o papel do professor e uma aprendizagem mais significativa dos alunos são salientadas. As experiências comentadas, desenvolvidas em ambiente escolar, com grupos de alunos de Ensino Fundamental e Médio, possibilitaram uma série de reflexões a respeito de aspectos motivacionais, das competências a serem desenvolvidas e do processo de avaliação nesse contexto.

Palavras-chaves: Softwares Interativos, Autoria Multimídia, Ambientes de Aprendizagem.

\begin{abstract}
This article comments, briefly, theoretical basis, pedagogical implications and experiences of projects that involve research and authorship, in multimedia environments, aiming at to promote richer learning spaces. Thus, it presents aspects of the social changes and the school's and teacher's roles to motivate the incorporation of the New Technologies of Communication and Information in the school, through development projects.
\end{abstract}

Key-words: Interactive Software, Multimedia Authorizing, Learning Environments.

\footnotetext{
*Bacharel em Informática, Mestre em Ciência da Computação, Professora da Universidade Luterana do Brasil e do Colégio Marista Nossa Sechora do Rosário. E-mail: adrianac@ulbra.tche.br

* Bacharel em Matemática, Mestre em Educação, Professora da Faculdade da Serra Gaúcha. E-mail: márcia.cantelli@fsg.br
} 


\section{Introdução}

O termo multimídia vem sendo utilizado, há algum tempo, em diversos setores da sociedade. As empresas fazem uso da multimídia para vender seus produtos e conquistar seus clientes. Os resultados não poderiam ser mais promissores, afinal o termo multimídia já deixa claro o seu significado: muitos meios.

$\mathrm{Na}$ Educação, ele apareceu, a princípio, tímido, temeroso. Hoje, está sendo utilizado em grande escala e é difícil não percebê-lo. Mas não se trata apenas de um termo e sim de uma estratégia poderosa na utilização de múltiplos recursos que contemplam diferentes percepções do ser humano.

Tratando-se a multimídia da utilização de múltiplos recursos como textos, sons, imagens, animações, gráficos, simulações - combinados para produzirem um efeito desejado em alguma execução - cabe ao professor fazer um bom uso dela, em seu contexto pedagógico, de forma que venha a auxiliar a construção do conhecimento pelo educando (Valente 1997), respeitando estilos e ritmos de aprendizagem diferenciados.

A utilização dos múltiplos recursos não desenvolve por si só a performance intelectual dos indivíduos. Os processos cognitivos complexos são construídos gradativamente, degrau a degrau, no decorrer de toda a vida. A multimídia, então, pode acelerar e propiciar uma maior apreensão do que é trabalhado, através da grande quantidade de estímulos que, se não forem adequados, se transformarão em "ruídos" (Coscarelli 1998). É importante contribuir para que o aluno transforme seus pensamentos, desenvolva atividades criativas, compreenda conceitos, reflita sobre eles e, conseqüentemente, crie novos significados.

Ter acesso à informação não basta. É necessário saber lidar com ela: analisá-la, aprofundá-la, decodificá-la e, após, fazer uma síntese do que realmente interessa, do que é útil, do que transmite de novo, das relações que podem ser estabelecidas, aí, então, se estará construindo conhecimento. Ao contrário, ter-se-á um acúmulo desnecessário de materiais e recursos, sem saber o que fazer com eles.

É na pesquisa, na seleção e na síntese desse mundo de informações que o professor torna-se indispensável, como mediador e facilitador do processo de construção do conhecimento. Ele, no entanto, também precisa conhecer as possibilidades e dominar os recursos da multimídia, para que o conhecimento seja visto como um processo contínuo de pesquisa e múltiplas interações.

É nessa perspectiva que as reflexões são aqui apresentadas e os projetos relatados foram desenvolvidos.

\section{Tempos de Mudanças}

Com as transformações sociais e, conseqüentemente, das relações de trabalho, novas são as exigências em relação à educação. É preciso formar pessoas capazes de lidar com problemas a respeito dos quais ainda não temos idéia, a lidar com o inesperado e com a incerteza (Morin 2000). Neste contexto de mudanças, salientam-se 
competências importantes para a sobrevivência em um novo tempo - entre outras características, destacam-se as capacidades de:

- Planejar, trabalhar e decidir em grupo;

- Localizar, acionar e utilizar informações acumuladas, bem como buscar e relacionar adequadamente novas informações.

Percebe-se a necessidade crescente em interagir para a resolução de problemas, para a realização de tarefas - torna-se necessária a reunião de pessoas competentes em seus domínios do conhecimento para trabalharem em projetos comuns. A valorização das competências individuais e a articulação dessas, de maneira harmoniosa, durante o desenvolvimento de trabalhos em grupo, imprimem qualidade às atividades desenvolvidas.

Os estímulos aos quais a sociedade é exposta impulsionam uma mudança no papel da escola e com isso a necessidade de romper-se com velhos paradigmas educacionais, centrados em currículos fragmentados, em memorização e transmissão de informações. Hoje, busca-se o desenvolvimento da inteligência de forma coletiva, a partir das vivências do grupo, das trocas e de aprofundamento.

"Uma cultura tecnológica de base também é necessária para pensar as relações entre a evolução dos instrumentos (informática $e$ hipermídia), as competências intelectuais e a relação com o saber que a escola pretende formar. Pelo menos sob esse ângulo, as tecnologias novas não poderiam ser indiferentes a nenhum professor, por modificarem as maneiras de viver, de se divertir, de se informar, de trabalhar e de pensar. Tal evolução afeta, portanto, as situações que os alunos enfrentam e enfrentarão, nas quais eles pretensamente mobilizam e mobilizarão o que aprenderam na escola." (Perrenoud 2000)

Diante desta realidade, os professores deixam de ser líderes oniscientes e passam a ser orientadores que permitam aos estudantes navegarem, livremente, entre os recursos disponibilizados, evoluindo de rígidos livros-textos para softwares interativos e intercâmbios propiciadores de informações que transformem os conteúdos em formas geradas pelos próprios indivíduos, fazendo conhecimento e transformando informações e dados em algo consistente, profundo e duradouro - a aprendizagem (Chesneaux 1995).

"A característica interativa dos produtos multimídia possibilita que o manuseio de informações se dê de forma natural e não forçada. Nossa atividade cognitiva não funciona de forma linear, onde uma informação leva necessariamente a outra. Nosso aparato cognitivo trabalha com associações entre informações que nem sempre parecem lógicas. A multimídia permite uma aproximação ao trabalho cognitivo natural. Como as informações em um bom produto multimídia podem ser cruzadas, confrontadas e conjugadas a qualquer momento, além de poderem ser avaliadas nas mais variadas ordens e até desordenadamente, a multimídia torna-se uma fonte de informações que oferece poucos limites a atividade cognitiva normal.” (Primo 1996) 
Nesse novo contexto, a valorização de capacidades cognitivas individuais, valores pessoais e habilidades que favoreçam o trabalho em grupo assumem fundamental importância. Quer-se formar cidadãos atuantes em seu entorno social. Para tanto, é preciso trabalhar o "conhecimento como um todo complexo" (Morin 2000), construído a partir de complexas interações do sujeito com outros sujeitos e com o meio, respeitando as particularidades de cada um.

\section{Espaços Diferenciados de Aprendizagem}

As pessoas recebem, processam e apresentam as informações de maneiras diferentes, de acordo com seus estilos próprios de aprendizagem. Ao organizar espaços de aprendizagem, no mundo atual, é necessário considerar os estilos de aprendizagem dos envolvidos e prover formas distintas de trabalho com o intuito de motivar e envolver os educandos, de maneira participativa e responsável, em sua aprendizagem.

A nova concepção de educador deverá contemplar as qualidades de um orientador, facilitador do processo, que aprenda a repensar suas sínteses, a tomar atitudes provisórias, permanentemente, refeitas mediante perspectivas e resultados obtidos com a utilização da tecnologia e dos recursos multimediáticos por ele oferecidos (Moran 1997).

É necessário repensar o ensino e a aprendizagem, colocando-se numa postura de professor inovador, criando situações significativas e diferenciadas, cabendo propiciar diferentes situações "problemas" ao educando. Uma das formas de propiciar "problemas" seria a proposta de trabalhar através de uma pedagogia de projetos. Para Gardner (1995), os projetos constituem-se em fontes de criação, que passam por processos de pesquisa, aprofundamento, análise, depuração e criação de novas hipóteses.

Segundo Perrenoud (1999), por parte do professor, supõe-se "a competência de produzir situações sob medida, trabalhar com o que está à mão, sem temer o desvio de ferramentas ou de objetos concebidos para outros finais. Para trabalhar com situações-problemas, utiliza-se, por exemplo, de preferência softwares didáticos, aplicativos (...) que são auxiliares diários das mais diversas tarefas intelectuais".

Para que ambientes de aprendizagem baseado em computadores venham a possibilitar ganhos pedagógicos é necessário que sejam realizadas atividades fundamentais no processo de desenvolvimento do conhecimento, como idealização do projeto, a busca dos dados, a definição do problema, a execução, a depuração e a avaliação do que foi construído, comparando com o objetivo inicial e retroagindo sobre os aspectos significativos da atividade (Valente 1995).

"A inovação pedagógica consiste na implantação do construtivismo sócio-interacionista, ou seja, a construção do conhecimento pelo aluno mediado por um educador. Porém, se o educador dispuser dos recursos da informática, terá muito mais chance de entender os processos mentais, os conceitos e as estratégias utilizadas pelo aluno e, com essa informação, poderá intervir e colaborar de modo mais 
efetivo nesse processo de construção do conhecimento. (...) O uso do computador permite a realização do ciclo descrição-execuçãoreflexão-depuração-descrição, no qual novos conhecimentos podem ser adquiridos na fase da depuração. Quando uma determinada idéia não produz os resultados esperados, ela deve ser burilada, depurada ou incrementada com novos conceitos ou novas estratégias. Esse incremento constitui novos conhecimentos, que são construídos pelo aluno.” (Valente 1999)

$\mathrm{Na}$ confecção dos trabalhos, os alunos apropriam-se dos recursos tecnológicos disponíveis e buscam elaborar seus projetos com muita criatividade, responsabilidade e pesquisa. Em um ambiente multimídia, é possível criar canais de comunicação com o aluno através de suas múltiplas percepções, favorecendo a aprendizagem, não no sentido de minimizar o seu esforço, mas de oferecer a ele um ambiente rico para construção de seu conhecimento (Coscarelli 1998).

Dando ênfase à descoberta e à criação e possibilitando a formação de alunos capazes de construir a sua própria aprendizagem, de aprender a aprender - habilidade necessária para toda vida -, os alunos podem utilizar softwares multimídia interativos para desenvolver seus projetos. Com ferramentas de autoria multimídia utilizadas diretamente pelos alunos, é possível compartilhar informações e representá-las a partir de múltiplas perspectivas, através da combinação de textos, imagens, sons, animações, botões e efeitos, em um ambiente de estímulos multissensoriais.

"A multimídia interativa adequa-se particularmente aos usos educativos. É bem conhecido o papel fundamental do envolvimento pessoal do aluno no processo de aprendizagem. Quanto mais ativamente uma pessoa participar da aquisição de um conhecimento, mais ela irá integrar e reter aquilo que aprender. Ora, a multimídia interativa, graças à sua dimensão reticular ou não linear, favorece uma atitude exploratória, ou mesma lúdica, face ao material a ser assimilado. É, portanto, um instrumento bem adaptado a uma pedagogia ativa.” (Lévy 1993)

Em consonância com uma proposta pedagógica interacionista, os desejos e necessidades dos alunos e da sociedade, as escolas atualizam-se para formar cidadãos capazes lidar com as incertezas do futuro. A incorporação das Novas Tecnologias da Comunicação e da Informação de maneira adequada contribui significativamente para uma educação abrangente, integradora e permanente.

\section{Algumas Experiências}

Com o intuito de discutir as aplicações práticas da fundamentação acima apresentada, alguns projetos são relatados a seguir. Tais projetos foram desenvolvidos no Colégio Marista Nossa Senhora do Rosário, escola da rede particular, em Porto Alegre, RS.

\subsection{Uma Viagem Virtual pela América do Sul - Construção de um Álbum Multimídia}


Como desafio aos alunos da $7^{\mathrm{a}}$ série do Ensino Fundamental, lançou-se a proposta de construir um Álbum Multimídia de uma viagem imaginária pelos treze países da América do Sul. Nessa aventura, eles exploraram os pontos turísticos, aspectos físicos, históricos, sociais e culturais do continente, partindo de elementos combinados com a professora de Geografia, Néli Rejane Fagundes Gonçalves, desencadeadora do projeto. O projeto foi acompanhado, também, por professores de Língua Portuguesa e de Educação Artística. O trabalho foi desenvolvido em grupos de quatro alunos, favorecendo atitudes de cooperação e compartilhamento de informações.

O trabalho foi organizado em duas etapas. Na primeira, orientados em sala de aula e prévia ao ambiente informatizado, os alunos iniciaram suas pesquisas, coletaram e selecionaram materiais em revistas, livros, folders de agências de viagens, fotografias e CD’s de música, Internet e softwares variados. Cada imagem ou música pesquisada foi digitalizada e colocada à disposição de todos os alunos, oportunizando o compartilhamento desse material por todos os envolvidos no projeto. As informações selecionadas nessa etapa serviram de base para o início do trabalho.

No Laboratório de Informática, a pesquisa tornou-se constante, buscando complementar e aprofundar os estudos iniciados. Uma série de sites (páginas na Internet) sobre os países abordados e também características gerais sobre a América do Sul foram disponibilizados na página da escola para que os alunos pudessem consultálos no decorrer das aulas ou de qualquer lugar do mundo, a qualquer instante. A troca de informações entre integrantes de um mesmo grupo, entre os grupos e com o professor demonstrou o espírito de cooperação.

Paralelo à pesquisa, os alunos montaram seus próprios álbuns em um ambiente de autoria multimídia, permitindo a representação de suas idéias e resultados de suas descobertas através da combinação de diferentes mídias - textos informativos, mensagens orientativas, imagens, vídeos, músicas e efeitos. Nesse momento, relacionaram cada gravura ou vídeo selecionado por eles, acrescidos de efeitos e trilhas sonoras, com a pesquisa realizada.

Na realização da "viagem virtual", cada grupo, orientado por um conjunto de aspectos sugeridos de cada país, optou por onde iniciar seus estudos e como conduzilos, de acordo com seus interesses e motivação. Nesse espaço, quebra-se a estrutura tradicional de aula, na qual o professor apresenta um determinado assunto em um dado dia, sem oportunizar a escolha por parte do aluno. Ao contrário, o professor apresenta-se como mediador, oferecendo autonomia ao grupo para escolher a ordem em que os assuntos serão trabalhados, acrescentar aspectos de interesse e curiosidades ou notícias recentes dos países.

Durante o processo de construção do álbum, o professor interagiu com os diversos grupos, nos diversos pontos em que se encontravam, orientando-os no sentido de favorecer a busca e o entendimento dos assuntos abordados.

A avaliação aconteceu de forma constante e contínua, aula a aula, permitindo um acompanhamento efetivo do processo de trabalho, do envolvimento e do progresso de cada aluno no desenvolvimento do projeto. O produto final também foi avaliado, considerando o roteiro estabelecido, informações acrescentadas, correção dos assuntos 
abordados e adequação das mídias empregadas. Os alunos realizaram ainda uma autoavaliação, analisando aspectos de participação e atitudes individuais e em grupo, empenho na pesquisa e aproveitamento.

A questão da localização, seleção, síntese e aplicação das informações pesquisadas, além dos aspectos multissensoriais dos recursos utilizados, contribuiu para um maior envolvimento e uma participação mais ativa dos alunos do processo de aprendizagem, tornando o desenvolvimento do álbum um momento de aprofundamento cultural bastante prazeroso.

Depoimentos de alguns alunos são apresentados na sequiência:

- 'O trabalho de Geografia tem sido muito interessante, pois não estamos somente lendo os mesmos livros e ouvindo as mesmas explicações e sim criando álbuns de fotografias. Assim, certamente, nós vamos aprender muito mais e conhecer algumas curiosidades que, possivelmente, os livros usados em aula não nos proporcionariam. Também posso dizer que a avaliação está sendo bem feita, apesar do trabalho ser em grupos, cada um é avaliado pelo que está fazendo. O programa que estamos utilizando é simples e tem muitos recursos. Está sendo bem 'legal" este trabalho." M. B.

- 'O trabalho de Geografia é muito divertido, pois é bastante novo, bem diferente, porque não é aquela coisa de fazer prova e mais prova. Além de ser novo, ele é muito educativo, pois nós aprendemos sobre todos os países da América do Sul. A cada vez que nós procuramos e pesquisamos, aprofundamos mais ainda nossos conhecimentos. Essa oportunidade muito interessante oferecida pela escola é mais uma forma criativa de dar novas propostas de trabalho aos alunos. Espero que isso se repita e seja dessa forma, educando e não decorando." R.S.

- "Trabalhos como este não são muito difundidos. Contudo, no futuro, esta será a base da educação e da avaliação dos professores. Gostaríamos muito que esta fosse uma das maneiras de avaliar um aluno futuramente, pois o projeto nos ensinou curiosidades e informações relevantes sobre os países da América do Sul de uma forma natural. Sem nos darmos conta já estávamos aprendendo! Além do mais, estudamos de uma forma menos maçante e muito mais interessante! Com certeza aprendemos muito mais desta forma!” A. E., B. C., J. F. e L. A.

Com base no projeto desenvolvido e em sua avaliação por todos os envolvidos, podem ser destacados alguns resultados: um maior incentivo e gosto pela pesquisa - o trabalho com mídias diferenciadas faz com que a utilização de uma estimule a busca de outra, uma imagem diferente leva à pesquisa e à elaboração de um texto sobre o que ela representa; uma aprendizagem mais significativa e contextualizada; a valorização do trabalho em grupo, da divisão e complementação de tarefas; uma maior interatividade entre alunos e com o professor, já que o último é orientador/reorientador constante e a troca de materiais e estratégias entre os envolvidos é permanente; melhor relacionamento dos alunos com o professor, devido à aproximação que este tipo de abordagem propicia. 
Os alunos da $2^{\text {a }}$ série o Ensino Médio, orientados na disciplina de Física pela professora Berenice Helena Wiener Stensmann, pesquisaram e criaram seus próprios aplicativos. O trabalho foi desenvolvido em duplas, ao longo do ano, de forma que as etapas pudessem ser cumpridas gradativamente, permitindo ampla pesquisa, teórica e de campo, trocas entre os grupos e organização do todo.

A primeira etapa do trabalho consistiu em motivar os alunos para a pesquisa e a coleta de informações sobre os conceitos básicos que envolvem a Termodinâmica, tais como, calor, temperatura, máquina térmica e frigorífica e energia.

A partir das informações obtidas, os alunos passaram para a segunda etapa, na qual deviam, evidenciar, no cotidiano, a aplicação desses conceitos. Essa atividade exigiu que se estabelecessem novas relações entre os conhecimentos anteriores e uma complementação das pesquisas até então realizadas. Para que pudessem compreender o funcionamento de mecanismos como um motor à explosão ( 2 tempos e 4 tempos) ou à reação, uma geladeira ou um ar condicionado, os alunos voltaram à pesquisa, tanto teórica - através de leituras em enciclopédias, revistas especializadas ou livros de mecânica -, quanto de campo - visitando oficinas de automóveis, oficinas de ar condicionado e geladeira, empresas aéreas, laboratório de engenharia da PUC e UFRGS, entre outros.

Após esses estudos, os alunos buscaram identificar o impacto ecológico e as consequiências do uso e da fabricação dessas máquinas ao meio ambiente e aos seres vivos, como o efeito estufa, a destruição da camada de ozônio, o enfisema pulmonar, as doenças alérgicas devido à poluição, etc.

No Laboratório de Informática, os alunos organizam o material pesquisado e elaboram um aplicativo multimídia, em ambiente de autoria, apresentando os conceitos pesquisados, os resultados de suas descobertas e pequenas simulações criadas por eles.

A ferramenta de autoria é hoje a base da Informática na Educação e é através da sua utilização que alunos e professores criam seus aplicativos. Em função da combinação de recursos multimídia, esse tipo de ferramenta promove a elaboração de atividades prazerosas e criativas. Nessa perspectiva, é possível agregar sons, imagens, textos, vídeos, banco de dados, etc., aos conteúdos inerentes à sala de aula. O software de autoria passa a ser um ambiente de criação que permite ao aluno transformar as informações obtidas em conhecimento, no momento em que ele as depura. O ambiente de trabalho é cooperativo. O envolvimento desencadeia motivação, dinamismo e desenvolvimento de competências, assim como a assimilação dos conteúdos.

\section{Conclusão}

O desenvolvimento de projetos no espaço educacional traz consigo uma série de possibilidades pedagógicas relevantes (Machado 1998):

- Respeito à individualidade: o ritmo, os interesses e as habilidades dos envolvidos são contemplados em trabalhos dessa ordem. Cabe aos alunos 
negociarem, orientados por um professor mediador, sobre os temas dos projetos e a forma de desenvolvê-los;

- Simulação de situações: em um ambiente de desenvolvimento de projetos, é possível "criar" situações imaginárias, representativas de situações reais, permitindo a visualização de conceitos e a vivência de situações diferenciadas;

- Fornecer rico material: disponibilidade de material em quantidade e qualidade, possibilitando pesquisa, aprofundamento, análise, depuração de idéias e afirmação ou criação de novas hipóteses. Esses materiais devem permitir a manipulação em diferentes formas e proporcionar diferentes estímulos;

- Proporcionar um ambiente que realmente possa estimular e por conseqüência motivar: os alunos devem estar envolvidos em seu processo de aprendizagem, participando ativamente em todas as fases de aquisição de informações e construção do conhecimento;

- Fornecer suporte durante todo o processo através dos membros dos grupos e do professor mediador: todas as questões anteriores devem ser apoiadas por um professor inovador e orientador, permitindo aos alunos ganhos significativos de aprendizagem.

As Novas Tecnologias da Informação e da Comunicação apresentam espaços adequados ao trabalho por projetos, por possibilitarem o atendimento dos aspectos descritos acima. Em um ambiente com ricos estímulos, propiciados pela multimídia e pela ampla gama de informações disponíveis, os alunos participam ativamente da construção de seu conhecimento.

\section{Bibliografia}

CHESNEAUX, Jean. Modernidade Mundo. Petrópolis: Vozes, 1995.

COSCARELLI, Carla Viana. O uso da Informática como instrumento de ensino-aprendizagem. Revista Presença Pedagógica, v. 4, n. 20, p. 37-45, mar/abr, 1998.

GARDNER, Howard. Inteligências Múltiplas: a teoria na prática. Porto Alegre: Artes Médicas, 1995.

LÉVY, Pierre. As Tecnologias da Inteligência - O futuro do pensamento na era da Informática. Rio de Janeiro: Ed. 34, 1993.

MACHADO, Nilbo. Interdisciplinaridade Aplicada. São Paulo: Ed. Érica, 1998.

MORIN, Edgar. Os sete saberes necessários à educação do futuro. Brasília, DF: Ed. Cortez e UNESCO, 2000.

MORAN, José Manual. O Professor no contexto das novas tecnologias da comunicação e da informação. Palestra - VIII Seminário Nacional de Educação: Tecnologias da Comunicação de Informação. Universidade Luterana do Brasil, Canoas, 1997. 
PERRENOUD, Philippe. Dez novas competências para ensinar. Porto Alegre: Artes Médicas Sul, 2000.

PERRENOUD, Philippe. Construir as competências desde a escola. Porto Alegre: Artes Médicas Sul, 1999.

PRIMO, Alex Fernando Teixeira. Multimídia e educação. Revista de Divulgação Cultural, Blumenau, SC, ano 18, n. 60, p. 83-88, set/dez, 1996.

VALENTE, José Armando. A Linguagem e a Estética Logo. Centro de Informática na Educação / CIE - IBM Brasil, n. 2, nov/dez, 1995.

VALENTE, José Armando. O uso inteligente do computador na educação. Revista Pátio, ano I, n. 1, p. 19-21, mai/jul, 1997.

VALENTE, José Armando. Informática na educação: uma questão técnica ou pedagógica? Revista Pátio, ano 3, n. 9, p. 21-23, mai/jul 1999. 